\title{
Effectiveness of expiratory muscle strength training on expiratory strength, pulmonary function and cough in the adult population: a systematic review.
}

TEMPLEMAN, L., ROBERTS, F. 


\section{Accepted Manuscript}

Title: Effectiveness Of Expiratory Muscle Strength Training On Expiratory Strength, Pulmonary Function And Cough In The Adult Population: A Systematic Review

Authors: Lucy Templeman, Fiona Roberts

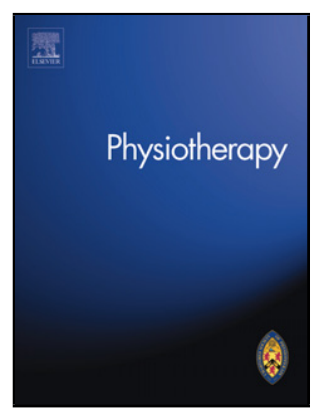

PII:

S0031-9406(19)30076-8

DOI: https://doi.org/10.1016/j.physio.2019.06.002

Reference: PHYST 1111

To appear in:

Physiotherapy

Please cite this article as: Templeman L, Roberts F, Effectiveness Of Expiratory Muscle Strength Training On Expiratory Strength, Pulmonary Function And Cough In The Adult Population: A Systematic Review, Physiotherapy (2019), https://doi.org/10.1016/j.physio.2019.06.002

This is a PDF file of an unedited manuscript that has been accepted for publication. As a service to our customers we are providing this early version of the manuscript. The manuscript will undergo copyediting, typesetting, and review of the resulting proof before it is published in its final form. Please note that during the production process errors may be discovered which could affect the content, and all legal disclaimers that apply to the journal pertain. 


\title{
Effectiveness Of Expiratory Muscle Strength Training On Expiratory Strength, Pulmonary Function And Cough In The Adult Population: A Systematic Review
}

\section{Affliations:}

Lucy Templeman ${ }^{a, b *}$ and Fiona Roberts ${ }^{a}$.

aSchool of Health Sciences, Robert Gordon University, Garthdee Road, Aberdeen, AB10 7QG, bNHS Grampian, Physiotherapy Outpatient Department, Woodend Hospital, Eday Road, Aberdeen AB15 6XS

*Corresponding author: Lucy Templeman, NHS Grampian, Physiotherapy Outpatient Department, Woodend Hospital, Eday Road, Aberdeen AB15 6XS. Tel: 01224556049 lucy.templeman@nhs.net

Word Count: 3132 (excluding abstract, references, tables, figures, legends)

\begin{abstract}
Background: Respiratory muscle strength declines in certain disease states, leading to impaired cough, reduced airway clearance and an increased risk of aspiration pneumonia. Respiratory muscle training may therefore reduce this risk.
\end{abstract}


Objectives: To assess current evidence of expiratory muscle strength training (EMST) on maximum expiratory pressure, cough flow and spirometry.

Data sources: Databases including CINAHL, Medline, Science Direct and PEDRo were searched.

Eligibility Criteria: Randomised controlled trials investigating expiratory muscle strength training on maximum expiratory pressure, pulmonary function or cough in any adult population, published before December 2017.

Study appraisal: Data were extracted to a trial description form and study quality evaluated by 2 reviewers. Meta-analysis was performed with calculation of mean differences and $95 \%$ confidence intervals.

Results: Nine studies met inclusion criteria and ranged in size from 12 to 42 participants. Trials investigated EMST in healthy adults (2), multiple sclerosis (3), COPD (2), acute stroke (1) and spinal cord injury (1). Overall, EMST improved maximum expiratory pressure $(15.95 \mathrm{cmH} 20 ; 95 \% \mathrm{CI}: 7.77$ to $24.12 ; \mathrm{p}<0.01)$ with no significant impact on cough flow (4.63L/min; $95 \%$ CI -27.48 to 36.74 ; $\mathrm{P}=0.78)$, forced vital capacity $(-0.16 \mathrm{~L} ; 95 \% \mathrm{CI}-0.35$ to $0.02 ; \mathrm{P}=0.09)$ or forced expiratory volume in 1 second $(-0.09 \mathrm{~L} ; 95 \% \mathrm{CI}-0.10$ to $-0.08 ; \mathrm{P}<0.001)$ versus control or sham training.

Conclusions: Meta-analysis indicated a small significant increase in maximum expiratory pressure following EMST. Improvements in maximum expiratory pressure did not lead to improvements in cough or pulmonary function.

Limitations: Variations in protocol design and population limited the overall effect size.

Funding: None 
Systematic Review Registration: PROSPERO (CRD42018104190).

\section{Contribution of Paper}

This review synthesises current EMST data on expiratory strength, pulmonary function and cough.

Despite differences in intervention protocols, meta-analysis indicated a small but statistically significant increase in maximum expiratory pressure following training. Few studies included secondary outcome measures of pulmonary function and cough flow with no evidence to support any change in airflow measures following EMST versus control or sham intervention.

The functional relevance of maximum expiratory pressure gains is yet to be determined. Physiotherapists and clinicians involved in pulmonary rehabilitation or with patients prone to aspiration should be advised that use of EMST alone for improving airway clearance mechanics is not supported. Further evidence of the relationship between expiratory strength and airway clearance is needed before EMST alone could be justified clinically to prevent aspiration.

Keywords: Expiratory muscle strength training, maximum expiratory pressure, aspiration pneumonia.

\section{INTRODUCTION}

Respiratory muscle function is vital for life: creating pressure differences needed for ventilation, eliminating airway secretions and protecting the airways [1]. 
Respiratory muscle strength and pressure is known to decline progressively with increasing age [2], possibly leading to inadequate ventilation and undermining normal airway protection [1]. Certainly the increased frequency of aspiration pneumonia in the elderly has been attributed to impaired airway protection such as reduced peak expiratory flow and cough [3]. Impaired respiratory strength is also observed in several disease states including chronic obstructive pulmonary disease (COPD) [4], Parkinson's disease (PD) $[5,6]$, multiple sclerosis (MS) $[7,8]$ and stroke [9], with reduced airway protection increasing the risk of aspiration pneumonia and hospital admission [10-12]. For this reason, respiratory muscle training becomes interesting as a strategy to reduce mortality from pneumonia.

The respiratory musculature comprises inspiratory and expiratory muscles with focus, to date, on inspiratory muscle training (IMT). Studies in healthy populations have demonstrated positive changes in respiratory muscle strength and diaphragm mobility following IMT $[13,14]$ with similar findings in patients with stroke, MS and PD $[15,16]$. Evidence also suggests respiratory weakness varies between diseases with expiratory muscles shown to weaken to a lesser extent than inspiratory in patients with COPD [17], but to a greater extent in MS [18]. From a functional perspective, expiratory muscles are known to have high activation for force generation during cough [19], therefore, specific expiratory weakness and impaired airway clearance may be responsible for the increased incidence of aspiration in patients prone to respiratory decline. Certainly studies in stroke suggest impairment of cough function is due to weakness of expiratory muscles rather than dysfunction at the level of the glottis [9]. Interventions targeting expiratory muscle strength therefore provide an attractive prophylaxis against aspiration pneumonia. 
Studies of Expiratory Muscle Strength Training (EMST) on maximum expiratory pressure (MEP) have been performed in different populations, but there is no consensus on the effects of EMST on MEP, airway clearance or other pulmonary measures with no systematic reviews or meta-analyses and just one narrative review published to date [20].

Consequently the aim of this systematic review was to investigate evidence for EMST on MEP in health and disease states. A secondary objective was to identify whether EMST alters spirometry or cough measures.

\section{Review question}

Does expiratory muscle strength training affect maximum expiratory pressure, cough flow or spirometry in adult populations?

\section{Methods}

Systematic Review and Meta Analysis

This quantitative systematic review protocol was prospectively registered with PROSPERO (CRD42018104190).

\section{Search Strategy}

A three-step search strategy was used. An initial, limited search of Medline and CINAHL was followed by analysis of text words and index terms. Using keywords 
identified, a second search was undertaken using CINAHL, Medline, Science Direct, PEDRo and Cochrane Central Register for Controlled Trials. All databases were searched from inception to end December 2017. Search terms were: Expiratory muscle strength training; expiratory training; OR Respiratory muscle strength training; AND expiratory pressure, maximum expiratory pressure, cough, sputum clearance. In a third step, references of retrieved studies were searched to identify further publications. To minimise publication bias, 'grey' literature was searched using Google Scholar. Due to limited resources for translation, only articles published in English were included.

\section{Study Design}

Randomised controlled trials (RCTs) only.

\section{Participants}

Studies of healthy adults and those with pulmonary, neurological or neuromuscular conditions were included. No upper age limit was defined.

\section{Interventions and Comparators}

Reports of threshold or resistance EMST were included. Combinations of interventions were excluded (e.g. inspiratory and expiratory training). Comparators were control intervention, sham EMST or breathing exercises.

\section{Outcome Measures}

The primary outcome measure was MEP. Secondary outcome measures included forced vital capacity $(\mathrm{FVC})$, forced expiratory volume in 1 second $\left(\mathrm{FEV}_{1}\right)$, and peak expiratory cough flow (PECF).

\section{Study selection}


On search completion, references were exported to Refworks, with duplicates identified and removed. Titles and abstracts were independently screened against inclusion criteria by two reviewers ( $L T$ and FR) and inclusion validated by discussion and consensus.

\section{Quality Assessment}

Methodological quality of each eligible article was assessed by two reviewers using the Critical Appraisal Skills Programme (CASP) RCT checklist [21]. Articles were assessed for risk of bias with any disagreement between reviewers resolved through discussion. In line with the Cochrane method, no quality threshold was defined with which to exclude studies, and only trials with RCT designs included [22].

Data Extraction, Synthesis and Analysis

Study details were extracted to a trial description form. Where sufficient information was available, Forrest plots were constructed using standardised mean differences for MEP, FVC, FEV 1 and cough, based on post intervention means.

Statistical heterogeneity was assessed using the inconsistency statistic $I^{2}$ [23]. All analyses were performed using Review Manager Software, version 5.0 (Cochrane Collaboration 2011, 5.0).

\section{Results}

Study Inclusion 
Literature searching identified 426 titles with 141 duplicates. Of the 285 abstracts screened, 31 were retrieved for full text review, of which nine $[7,17,18,24-29]$ met all inclusion criteria and underwent quality assessment, data extraction and analysis (Fig. 1).

\section{Methodological Quality}

All studies reported random allocation of participants in an effort to reduce selection bias, however assessment of true randomisation was not possible as no studies provided recruitment sampling methods. Blinding of participants and staff to group allocation was performed in six studies $[7,24-29]$. Compliance of attrition reporting was high with rates from $0[17,29]$ to $23[26]$ patients, with varied reasons for attrition. Of note, Gosselink et al. [18] reported patients who were unable to perform MEP measurements due to severely impaired lung function.

Study Description: RCTs investigated EMST in healthy individuals $(2[17,29])$, patients with COPD $(2[35,28])$ and subjects with neurological conditions including MS (3 $[7,18,27])$, spinal cord injury (SCI; $1[26])$ and acute stroke (1 $[24])$.

\section{Participants}

The number of study participants ranged from 12 [17] to 42 [24], with 236 participants across all studies. Only Gosselink et al. [18] and Kulnik et al. [24] performed power analysis for sample size calculation.

Subjects' mean age ranged from 24 [29] to 66 years [25]. As neither Smeltzer et al. [7] nor Silverman et al. [27] reported participant age, a mean age across studies could not be calculated (Table 1 ). 


\section{Intervention and comparators}

All studies used threshold/resistance loading of the expiratory muscles although training devices varied between studies (Table 2) with five using a modified Threshold Inspiratory Muscle Trainer $[7,17,18,25,28]$ and three using a Threshold Positive Expiratory Pressure (PEP) device $[24,27,29]$. Roth and colleagues [26] used a closed end, high-pressure force meter with subjects exhaling maximally against a pressure gauge. All studies assessed MEP as a primary outcome measure with three including cough $[18,24,29]$ or spirometry outcomes $[25,26,29]$.

Of the included studies, only those in healthy subjects $[17,29]$ compared EMST to a control with no intervention. All remaining studies included breathing exercises [18] or sham EMST as a comparator [7,24-28].

\section{Outcome 1: Expiratory Muscle Strength}

Overall meta-analyses included a total of 213 patients and favoured EMST intervention with a small but significant improvement in MEP of $15.95 \mathrm{cmH}_{2} \mathrm{O}$ (95\% CI: 7.77 to $24.12 ; \mathrm{p}<0.001 ;$ Fig $2 \mathrm{~A}$ ) compared with control/sham. To investigate sources of heterogeneity $\left(I^{2}>50 \%\right)$ across studies, sub-analyses were performed by pathology.

\section{Healthy Populations}

In both RCTs investigating EMST with healthy subjects $[17,29]$, populations were of similar age (mean age $\leq 30$ ) with baseline MEP values in line with reported norms [30] and no significant differences between groups at baseline. Both studies used a 4-week $30 \%$ threshold training programme comprising two 15- 
minute sets of training daily for 4 weeks. Each reported significant increases in MEP versus control. Meta-analysis comprised 34 healthy participants, with high homogeneity $\left(I^{2}=0 \%\right)$, suggesting EMST significantly improved MEP with a mean difference of $33.62 \mathrm{cmH}_{2} \mathrm{O}(95 \% \mathrm{CI} 16.38$ to $50.85 ; \mathrm{p}<0.0001)$ versus control (Fig 2B).

COPD

Two studies investigated MEP in patients with COPD $[25,28]$. Whilst both reported no difference between groups at baseline, actual MEP values varied considerably between studies. Weiner et al. [28] reported lower baseline MEP than predicted values for the equivalent age category [31], whilst Mota et al. [25] recorded pressures greater than some reported norms for MEP [30] Despite these differences, both studies trained muscle endurance with 30-minute training sessions at $50-60 \%$ of MEP, although Weiner [28] used a longer 12-week training period. Forrest plots identified good homogeneity between studies $\left(I^{2}=0 \%\right)$ and meta-analysis, with a total of 39 patients with COPD, suggested EMST significantly improved MEP in COPD with a standard mean difference of $19.93 \mathrm{cmH}_{2} \mathrm{O}$ (8.88 to $30.97 ; \mathrm{p}=0.0004$ ) versus control (Fig $2 \mathrm{C}$ ).

\section{Multiple Sclerosis}

Three studies investigated MEP in patients with MS $[7,18,27]$. Gosselink (2000) and Smeltzer (1996) reported reduced baseline MEP to 29\% [18] and 36.9\% [7] of predicted normative values respectively. The most recent study [27] reported higher baseline MEP values with no comparison to normal values.

All three studies used a similar protocol using daily sets (15-25 repetitions) of MEP at $50 \%, 75 \%$ or maximal resistance. The earlier studies $[7,18]$ both 
employed a 12-week protocol and reported significant improvements in MEP following EMST. Meta-analysis of the three studies, with a total of 69 patients showed considerable heterogeneity $\left(I^{2}=61 \%\right)$ and no significant change in MEP following EMST $\left(11.29 \mathrm{cmH}_{2} \mathrm{O}(-0.32\right.$ to $22.91 ; \mathrm{p}<0.06)$ versus sham (Fig 2D).

\section{Stroke}

One study [24] investigated EMST in patients within 2 weeks of stroke onset $(n=42)$. Baseline MEP values were not significantly different between groups but reduced compared to age-matched normal values. Only $52 \%$ of patients completed more than $70 \%$ of the 4 -week training programme with significant improvement in MEP in intervention and control groups (Mean (SD) change in MEP EMST $12(15) \mathrm{cmH}_{2} \mathrm{O}$ versus sham 12(18) $\left.\mathrm{cmH}_{2} \mathrm{O}, \mathrm{p}=0.35\right)$.

\section{Spinal Cord Injury}

One RCT [26] investigated EMST in 29 patients with motor-complete spinal cord injury at or above T1. There was no difference between groups at baseline with MEP lower than age-matched norms [31]. Following a strength training protocol of 10 maximal expirations twice daily for 6-weeks, significant improvements in MEP were seen in the training group versus sham (Mean (SD) change in MEP EMST 35(38.4) $\mathrm{cmH}_{2} \mathrm{O}$ versus sham 8(19.1) $\left.\mathrm{cmH}_{2} \mathrm{O}, \mathrm{p}=0.002\right)$.

\section{Outcome 2: Cough}

Three studies included cough as a secondary outcome measure $[18,24,29]$. Sasaki [29] and Kulnik et al. [24] assessed PECF outcomes following 4-week EMST in healthy subjects and patients following acute stroke, respectively. Baseline PECF was normal in patients after acute stroke [24]. Both intervention and sham groups demonstrated increases in PECF over time, with no significant difference between groups. In healthy subjects, Sasaki [29] found no change in 
PECF following EMST. Despite differences in age and baseline MEP, PECF data between studies showed good homogeneity $\left(I^{2}=8 \%\right)$ and indicated no significant impact of EMST on PECF (4.63L/min; $95 \% C I-27.48$ to $36.74 ; \mathrm{P}=0.78 ;$ Figure 3 ).

Gosselink et al. [18] assessed cough efficacy by means of the validated pulmonary index (PI) for patients with MS [32], reporting significant improvements versus control following EMST. The PI includes patient- and examiner-rated ability to clear the airway, however the authors provided no detail on components of the index that improved following training.

\section{Outcome 3: Pulmonary Function}

Three studies $[25,26,29]$ included pulmonary function as outcome measures, reporting FEV1 or FVC. Roth et al. [26] demonstrated small increases in FVC and $\mathrm{FEV}_{1}$ in intervention and sham groups, whilst Mota [25] and Sasaki [29] found no change in any measure of pulmonary function following EMST. Forrest plots indicated good homogeneity $\left(I^{2}=0 \%\right)$ with no evidence to support EMST in improving FVC $(-0.16 \mathrm{~L} ; 95 \% \mathrm{CI}-0.35$ to $0.02 ; \mathrm{P}=0.09 ;$ Fig $4 \mathrm{~A})$ or $\mathrm{FEV}_{1}(-0.09 \mathrm{~L}$; $95 \%$ CI -0.10 to $-0.08 ; \mathrm{P}<0.001 ;$ Fig $4 \mathrm{~B})$.

\section{Discussion}

This review aimed to assess the evidence for EMST on maximum expiratory pressure in different adult populations. Meta-analysis indicated a small but significant increase in expiratory pressure following EMST, representing an improvement of approximately $15 \%$ in MEP. There was no evidence of any effect of EMST on peak cough flow or spirometry.

As expiratory training is a potential intervention to improve airway clearance, determining its effectiveness by clinical population is paramount. Further meta- 
analysis by patient population also indicated an increase in MEP following expiratory training that reached significance in young healthy adults and those with COPD, but not in patients with MS. This is in line with a recent Cochrane review of respiratory training in MS that failed to find sufficient evidence to support expiratory training or breathing exercises on MEP [33].

Only single RCTs were available in patients with SCI or stroke, precluding metaanalysis. Similar to MS findings, data in patients following acute stroke showed no significant increase in MEP following training, however in patients with spinal cord injury, maximal resistance training significantly increased MEP. Differences in disease pathology across these groups may impact patients' ability to comply with training and account for some of this variation. Facial weakness and reduced lip closure strength have been documented in patients with MS [34] and stroke [35] respectively, affecting ability to achieve and maintain a mouth seal during expiratory training. In the current MS studies, Gosselink et al, [18] excluded patients due to inability to generate mouth pressures, while Silverman et al, [27] mentioned insufficient facial strength as possible exclusion criteria. As each of these studies used near-maximal or maximal strength training, it is conceivable that difficulties maintaining the buccal pressures generated during EMST may have limited the effects of muscle training. Conversely in patients following SCI, where oromotor control is not routinely affected, maximal resistance training was tolerated resulting in significant improvements in MEP versus control.

In COPD, where evidence suggests that up to $20 \%$ of patients with severe disease have insufficient inspiratory strength to generate peak flow requirements for inhalation delivery devices [36], patients tolerated EMST well with a significant increase seen in MEP. This may be due to use of a lower intensity "resistive breathing" protocol (up to 60\% expiratory pressure training), rather 
than strength-based near maximal "threshold loading". Although resistive breathing and threshold loading have been shown to generate similar workloads in inspiratory training [37], the higher pressures generated during maximal resistance loading may not be tolerable in patient populations prone to respiratory muscle weakness.

The small effect size of EMST may have been due to the lack of a standardized intervention protocol and duration across studies. Firstly, the different training devices used were neither designed nor validated for expiratory muscle training. The Threshold IMT is validated as a reliable method of loading inspiratory muscles [38] but there is no equivalent study on modification for expiratory loading. Similarly, Threshold PEP was designed as an adjunct to mobilise airway secretions and prevent atelectasis, with studies validating its reliability for muscle training/loading lacking.

Secondly, a lack of training specificity may also have weakened the size of the training effect seen. In terms of muscle physiology, short 4-week periods of training are sufficient to initiate neural changes such as increased motor unit recruitment and firing rates [39], but not to elicit changes in muscle fibre strength [39]. Current studies in healthy individuals both identified increases in MEP after just 4 weeks in line with broader literature [40]. However, evidence suggests training programmes of at least 6 weeks duration, are needed to generate sustainable, measurable changes in muscle fibre hypertrophy [41]. From a clinical perspective, as post-intervention MEP values in COPD, stroke and MS studies all remained below normal for their respective age category [30], extending the duration of EMST may have been more effective in achieving outcomes closer to normal/predicted MEP levels, although patient adherence to longer interventions may prove difficult. 
Gains of $15 \%$ expiratory strength may represent statistically significant changes in MEP, however the clinical significance of these changes is unclear. Critical MEP levels have been proposed $\left(40 \mathrm{cmH}_{2} \mathrm{O}\right)$, below which secretions are thought to accumulate in the larynx [42], however the minimal MEP improvement needed to impact airway clearance has yet to be determined. Correlations between MEP and cough have been documented in SCI where a $10 \mathrm{cmH}_{2} \mathrm{O}$ increase in MEP has been shown to generate $0.15 \mathrm{~L} / \mathrm{sec}$ improvements in PECF [43], however the functional benefits of this have not been determined. The current meta-analysis did not support EMST effects on cough flow, with several factors likely affecting this. In addition to the paucity of data, the lack of cough flow impairment in the populations studied may have limited the potential for improvement, there may have been insufficient improvement in MEP in order to impact cough efficacy, or these findings may be the result of inadequate training specificity. It has been suggested that expiratory muscles need to be trained close to residual volume to improve expiratory capacity and flow [32], however current studies performed training closer to total lung capacity. This highlights the importance of accurate intervention design and the selection of outcome measures that are proven to be sensitive to the intervention in question. It may be that other measures of cough, such as the pulmonary index [18], are more sensitive to changes in MEP.

In line with previous quasi-experimental studies [8] current meta-analysis suggested no significant effect of EMST on either FEV 1 or FVC. Proposed explanations for this suggest elastic recoil and properties of the lung tissue, rather than expiratory muscle strength, may determine maximum expiratory flow [29]. Certainly changes to lung tissue in chronic diseases such as MS are known to impair lung compliance to a greater extent than skeletal muscle weakness [8]. One recent systematic review has suggested combined expiratory and inspiratory training may have a greater impact on pulmonary function by 
enhancing inspiratory reserve volume and elastic recoil, and generating significant improvements in $\mathrm{FEV}_{1}[44]$.

\section{Limitations}

The potential to overestimate the current treatment effect, due to the small number of eligible studies, small sample sizes, variation in age, population and intervention design, must be considered when interpreting the present results.

\section{Conclusion}

This review aimed to assess and synthesise current EMST data and determine the effect of EMST on expiratory strength, pulmonary function and cough. Nine studies examined MEP as a primary outcome measure and, despite differences in intervention protocols, meta-analysis indicated a small but statistically significant increase in MEP following EMST. Limited studies included outcome measures of pulmonary function or cough with no evidence to support any change in airflow measures following EMST.

\section{Implications for Research}

Methodological variation across studies offers direction for future research to determine the most effective training protocol for MEP gains. As cough and spirometry measures were not sensitive to MEP changes, investigation of other functional outcomes such as dyspnoea may help identify a role for improvements in MEP. Future EMST research may best be conducted as one arm of larger interventions using combined inspiratory and expiratory muscle training.

\section{Implications for Clinical Practice}

Populations prone to expiratory muscle weakness have been shown to respond to EMST, however the functional relevance of this is yet to be determined. As a link 
has not yet been demonstrated between increased MEP and improved airway clearance, physiotherapists and clinicians involved in treatment of patients prone to aspiration should undertake EMST with caution.

Ethical Approval: None

Funding: This research did not receive any specific grant from funding agencies in the public, commercial, or not-for-profit sectors.

Conflict of Interest: None

Declarations of interest: None

\section{REFERENCES}

1. Sanches VS, Santos FM, Fernandes JM, Santos MLM, Müller PT and Gustavo Christofoletti G. Neurodegenerative disorders increase decline in respiratory muscle strength in older adults. Respiratory Care $2014 ; 59(12): 1838-45$.

2. Pessoa I, Sclauser MB, Parreira VF, Fregonezi GA, Sheel AW, Chung F, et al. Reference values for maximal inspiratory pressure: a systematic review. Canadian Respiratory Journal. 2014; 21(1):43-50.

3. Janssens JP, Krause KH. Pneumonia in the very old. The Lancet Infectious Diseases. 2004; 4(2):112-24. 
4. Gosselink R, Troosters T, Decramer M. Distribution of muscle weakness in patients with stable chronic obstructive pulmonary disease. Journal of Cardiopulmonary Rehabilitation and Prevention. 2000; 20(6):353-60.

5. Silverman EP, Sapienza CM, Saleem A, Carmichael C, Davenport PW, Hoffman-Ruddy $B$, et al. Tutorial on maximum inspiratory and expiratory mouth pressures in individuals with idiopathic Parkinson disease (IPD) and the preliminary results of an expiratory muscle strength training program. NeuroRehabilitation. 2006; 21(1):71-9.

6. Ambrosino N, Carpene N, Gherardi M. Chronic respiratory care for neuromuscular diseases in adults. European Respiratory Journal. 2009; $34(2): 444-51$

7. Smeltzer SC, Levietes MH, Cook SD. Expiratory training in multiple sclerosis. Archives of Physical Medicine and Rehabilitation. 1996; 77(9):909-12.

8. Chiara T, Martin AD, Davenport PW, Bolser DC. Expiratory muscle strength training in persons with multiple sclerosis having mild to moderate disability: effect on maximal expiratory pressure, pulmonary function, and maximal voluntary cough. Archives of Physical Medicine and Rehabilitation. $2006 \mathrm{Apr}$ $1 ; 87(4): 468-73$

9. Harraf F, Ward K, Man W, Rafferty G, Mills K, Polkey M, et al. Transcranial magnetic stimulation study of expiratory muscle weakness in acute ischemic stroke. Neurology. 2008 Dec 9;71(24):2000-7.

10. Kulnik ST, Birring SS, Hodsoll J, Moxham J, Rafferty GF, Kalra L. Higher cough flow is associated with lower risk of pneumonia in acute stroke. Thorax. 2016 May $1 ; 71(5): 474-5$. 
11. Hannawi Y, Hannawi B, Rao CP, Suarez JI, Bershad EM. Stroke-associated pneumonia: major advances and obstacles. Cerebrovascular Diseases. $2013 ; 35(5): 430-43$.

12. Pinter B, Diem-Zangerl A, Wenning GK, Scherfler C, Oberaigner W, Seppi K, et al. Mortality in Parkinson's disease: a 38-year follow-up study. Movement Disorders. 2015 Feb;30(2):266-9.

13. Mills DE, Johnson MA, Barnett YA, Smith WH, Sharpe GR. The effects of inspiratory muscle training in older adults. Medicine \& Science in Sports \& Exercise. $2015 ; 47(4): 691-7$.

14. Souza H, Rocha T, Pessoa M, Rattes C, Brandão D, Fregonezi G, et al. Effects of inspiratory muscle training in elderly women on respiratory muscle strength, diaphragm thickness and mobility. Journals of Gerontology Series A: Biomedical Sciences and Medical Sciences. 2014 Nov 13;69(12):1545-53.

15. Messaggi-Sartor M, Guillen-Solà A, Depolo M, Duarte E, Rodríguez DA, Barrera MC, et al. Inspiratory and expiratory muscle training in subacute stroke: a randomized clinical trial. Neurology. 2015 Aug 18;85(7):564-72.

16. Reyes A, Ziman M, Nosaka K. Respiratory muscle training for respiratory deficits in neurodegenerative disorders: a systematic review. Chest. 2013 May $1 ; 143(5): 1386-94$

17. Suzuki S, Sato M, Okubo T. Expiratory muscle training and sensation of respiratory effort during exercise in normal subjects. Thorax. $1995 \mathrm{Apr}$ $1 ; 50(4): 366-70$. 
18. Gosselink R, Kovacs L, Ketelaer P, Carton H, Decramer M. Respiratory muscle weakness and respiratory muscle training in severely disabled multiple sclerosis patients. Archives of Physical Medicine and Rehabilitation. 2000 Jun $1 ; 81(6): 747-51$.

19. Bolser DC, Reier PJ, Davenport PW. Responses of the anterolateral abdominal muscles during cough and expiratory threshold loading in the cat. Journal of Applied Physiology. 2000 Apr 1;88(4):1207-14.

20. Laciuga H, Rosenbek JC, Davenport PW, Sapienza CM. Functional outcomes associated with expiratory muscle strength training: narrative review. Journal of Rehabilitation Research \& Development. 2014 Apr 1;51(4).

21. Critical Appraisal Skills Programme (CASP), 2018. CASP Systematic Review Checklist [online]. Available at: https://casp-uk.net/casp-tools-checklists/ Accessed: 10 Jan 2018.

22. Cochrane Collaboration. Cochrane handbook for systematic reviews of interventions. Cochrane Collaboration; 2008.

23. Higgins JP, Thompson SG, Deeks JJ, Altman DG. Measuring inconsistency in meta-analyses. BMJ: British Medical Journal. 2003 Sep 6;327(7414):557.

24. Kulnik ST, Birring SS, Moxham J, Rafferty GF, Kalra L. Does respiratory muscle training improve cough flow in acute stroke? Pilot randomized controlled trial. Stroke. 2015 Feb;46(2):447-53.

25. Mota S, Güell R, Barreiro E, Solanes I, Ramírez-Sarmiento A, Orozco-Levi M, et al. Clinical outcomes of expiratory muscle training in severe COPD patients. Respiratory Medicine. 2007 Mar 1;101(3):516-24. 
26. Roth EJ, Stenson KW, Powley S, Oken J, Primack S, Nussbaum SB, et al. Expiratory muscle training in spinal cord injury: a randomized controlled trial. Archives of Physical Medicine and Rehabilitation. 2010 Jun 1;91(6):857-61.

27. Silverman EP, Miller S, Zhang Y, Hoffman-Ruddy B, Yeager J, Daly J]. Effects of expiratory muscle strength training on maximal respiratory pressure and swallow-related quality of life in individuals with multiple sclerosis. Multiple Sclerosis Journal-Experimental, Translational and Clinical. 2017 May;3(2):2055217317710829.

28. Weiner $P$, Magadle $R$, Beckerman $M$, Weiner $M$, Berar-Yanay N. Specific expiratory muscle training in COPD. Chest. 2003 Aug 1;124(2):468-73.

29. Sasaki M. The effect of expiratory muscle training on pulmonary function in normal subjects. Journal of Physical Therapy Science. 2007;19(3):197-203.

30. Wohlgemuth M, Van der Kooi EL, Hendriks JC, Padberg GW, Folgering HT. Face mask spirometry and respiratory pressures in normal subjects. European Respiratory Journal. 2003 Dec 1;22(6):1001-6.

31. Wilson SH, Cooke NT, Edwards RH, Spiro SG. Predicted normal values for maximal respiratory pressures in caucasian adults and children. Thorax. 1984 Jul $1 ; 39(7): 535-8$

32. Smeltzer SC, Lavietes MH, Troiano R, Cook SD. Testing of an index of pulmonary dysfunction in multiple sclerosis. Nursing Research. 1989;38(6):3704. 
33. Rietberg MB, Veerbeek JM, Gosselink R, Kwakkel G, van Wegen EE. Respiratory muscle training for multiple sclerosis. The Cochrane Library. 2017 Jan 1.

34. Tzelepis GE, McCool FD. Respiratory dysfunction in multiple sclerosis. Respiratory Medicine. 2015 Jun 1;109(6):671-9.

35. Dai R, Lam OL, Lo EC, Li LS, Wen Y, McGrath C. Orofacial functional impairments among patients following stroke: a systematic review. Oral Diseases. 2015 Oct;21(7):836-49.

36. Gosselink R, De Vos J, Van den Heuvel SP, Segers J, Decramer M, Kwakkel G. Impact of inspiratory muscle training in patients with COPD: what is the evidence?. European Respiratory Journal. 2011 Feb 1;37(2):416-25.

37. Belman MJ, Botnick WC, Nathan SD, Chon KH. Ventilatory load characteristics during ventilatory muscle training. American Journal of Respiratory and Critical Care Medicine. 1994 Apr;149(4):925-9.

38. Alwohayeb NS, Alenazi BA, Albuainain FA, Alrayes MM. A Comparison between Two Types of Resistive Inspiratory Muscle Training Devices in Normal Subjects in Regards to Pulmonary Functions. Int J Phys Med Rehabil. 2018; 6:449.

39. Beck TW, DeFreitas JM, Stock MS. The effects of a resistance training program on average motor unit firing rates. Clinical Kinesiology (Online). 2011 Apr $1 ; 65(1): 1$.

40. Baker S, Davenport P, Sapienza C. Examination of strength training and detraining effects in expiratory muscles. Journal of Speech, Language, and Hearing Research. 2005 Dec 1;48(6):1325-33. 
41. Seynnes OR, de Boer M, Narici MV. Early skeletal muscle hypertrophy and architectural changes in response to high-intensity resistance training. Journal of applied physiology. 2007 Jan;102(1):368-73.

42. Oda AL, Bolzan DW, Cruz CT, Oliveira AS, Raimundo RD. Correlation of the Maximal Respiratory Pressures, Respiratory Airflow and Dysphagia in Patients with Acquired Autoimmune Myasthenia Gravis. Austin J Musculoskelet Disord. $2016 ; 3(1): 1031$.

43. Postma K, Vlemmix LY, Haisma JA, de Groot S, Sluis TA, Stam HJ, Bussmann JB. Longitudinal association between respiratory muscle strength and cough capacity in persons with spinal cord injury: An explorative analysis of data from a randomized controlled trial. Journal of Rehabilitation Medicine. 2015 Sep $5 ; 47(8): 722-6$

44. Gomes-Neto M, Saquetto MB, Silva CM, Carvalho VO, Ribeiro N, Conceição CS. Effects of respiratory muscle training on respiratory function, respiratory muscle strength, and exercise tolerance in patients poststroke: a systematic review with meta-analysis. Archives of Physical Medicine and Rehabilitation. 2016 Nov 1;97(11): 1994-2001. 
Figure 1: PRISMA Flowchart of Search and Selection Criteria
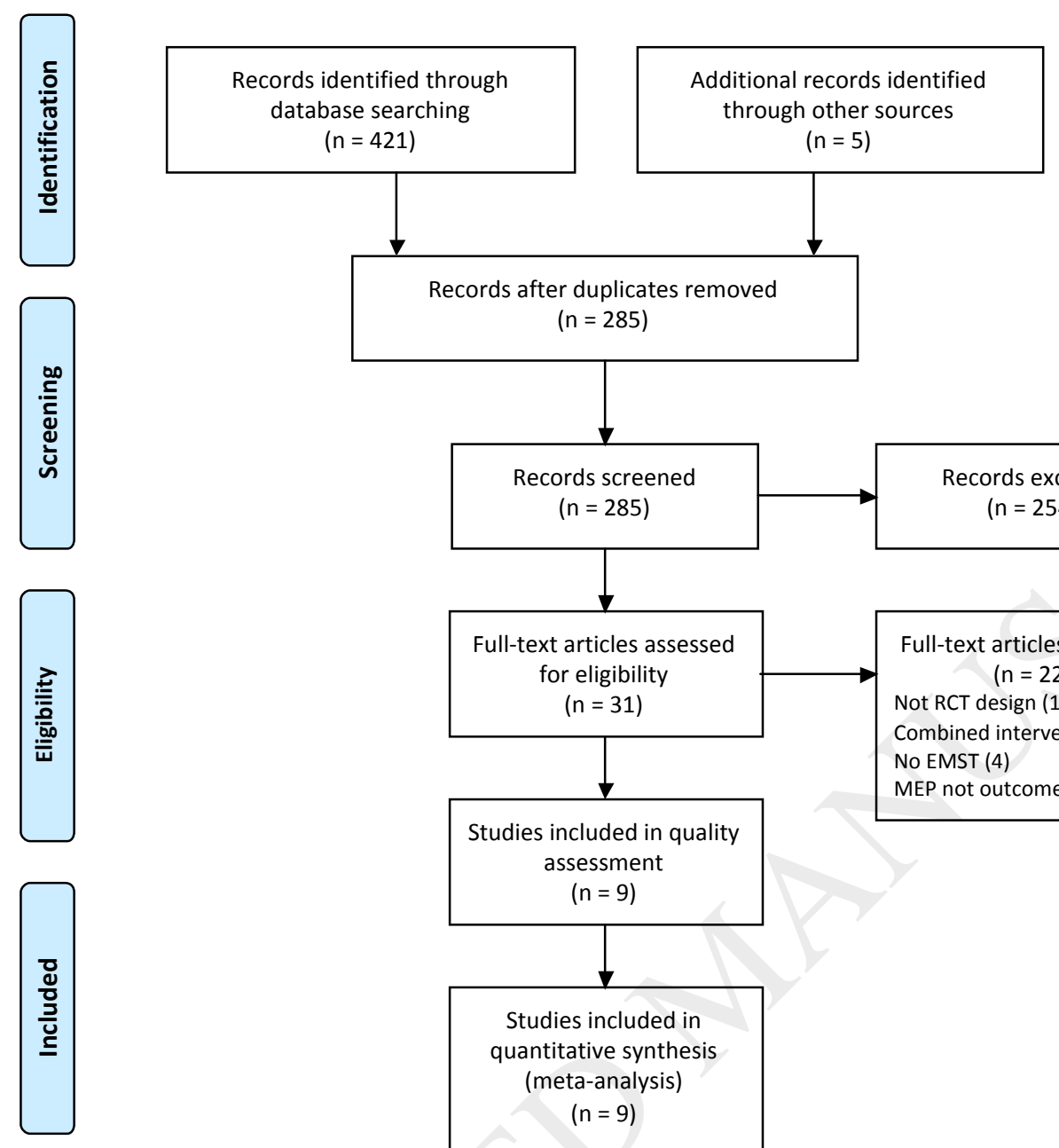

Records after duplicates removed $(n=285)$

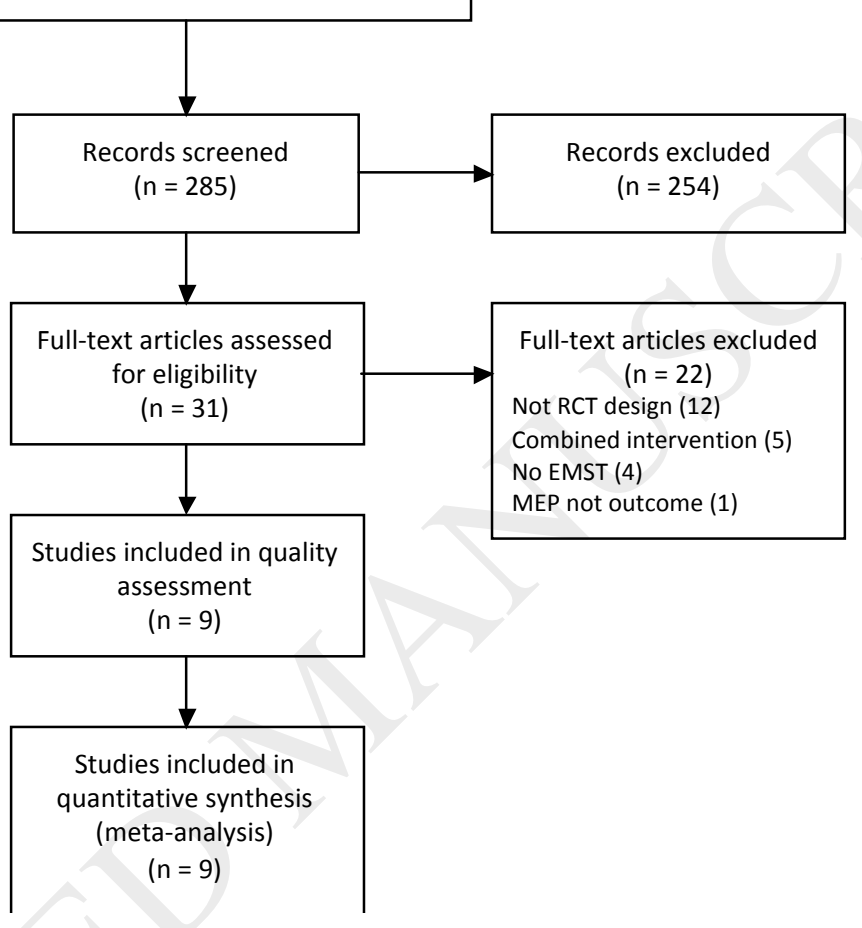


Table 1: Characteristics of Included Studies

\begin{tabular}{|c|c|c|c|c|c|c|}
\hline \multirow{2}{*}{$\begin{array}{l}\text { Study (year) } \\
\text { Country [ref] }\end{array}$} & \multirow{2}{*}{$\begin{array}{l}\text { Patients } \\
(\mathrm{N}, \text { mean age, sex })\end{array}$} & \multirow[t]{2}{*}{ Population } & \multicolumn{3}{|c|}{ Outcome measures } & \multirow[t]{2}{*}{ Key Findings } \\
\hline & & & MEP & PFT & Cough & \\
\hline $\begin{array}{l}\text { Sasaki (2007) } \\
\text { Japan [29] }\end{array}$ & $\begin{array}{l}N=33,24 y, 70 \% \text { male } \\
(n=22 \text { completed })\end{array}$ & Healthy & $\checkmark$ & FVC FEV 1 & PECF & $\begin{array}{l}\text { * MEP improved in EMST group compared with control } \\
(p<0.05) \text {, with no change in spirometry or PECF }\end{array}$ \\
\hline $\begin{array}{l}\begin{array}{l}\text { Suzuki et al. } \\
(1995) \\
\text { Japan [17] }\end{array} \\
\end{array}$ & $\mathrm{N}=12,30 \mathrm{y}, 100 \%$ male & Healthy & $\checkmark$ & - & - & $\begin{array}{l}\text { * MEP improved in EMST group compared with control } \\
(p<0.05) \text {. }\end{array}$ \\
\hline $\begin{array}{l}\text { Gosselink et al. } \\
(2000) \\
\text { Belgium [18] }\end{array}$ & $\begin{array}{l}N=21,58 y, 46 \% \text { male } \\
(n=18 \text { completed })\end{array}$ & MS & $\checkmark$ & - & PI & $\begin{array}{l}\text { No significant increase in MEP post training. } \\
\text { PI increased }(p<0.05) \text { vs baseline and control. }\end{array}$ \\
\hline $\begin{array}{l}\text { Silverman } \\
(2017) \\
\text { USA [27] }\end{array}$ & $\begin{array}{l}\mathrm{N}=42, \text { not reported, } \\
26 \% \text { male } \\
(\mathrm{n}=36 \text { completed })\end{array}$ & MS & $\checkmark$ & - & - & No significant increase in MEP post training vs sham \\
\hline $\begin{array}{l}\text { Smeltzer et al. } \\
(1996) \\
\text { USA [7] }\end{array}$ & $\begin{array}{l}\mathrm{N}=15, \text { not reported, } \\
46 \% \text { males }\end{array}$ & MS & $\checkmark$ & - & - & * MEP increased $(p<0.005)$ post training vs sham. \\
\hline $\begin{array}{l}\text { Mota et al. } \\
(2007) \\
\text { Spain [25] }\end{array}$ & $\mathrm{N}=16,66 \mathrm{y}, 100 \%$ male & $\begin{array}{l}\text { COPD } \\
\text { GOLD III \& IV }\end{array}$ & $\checkmark$ & FVC FEV 1 & - & $\begin{array}{l}\text { * MEP improved in EMST group vs sham }(p<0.05) \text {, } \\
\text { with no significant changes in spirometry. }\end{array}$ \\
\hline $\begin{array}{l}\text { Weiner et al., } \\
\text { (2003) } \\
\text { Israel [28] }\end{array}$ & $\begin{array}{l}N=26,62 y, 85 \% \text { male } \\
(n=23 \text { completed })\end{array}$ & $\begin{array}{l}\text { COPD, GOLD } \\
\text { III \& IV }\end{array}$ & $\checkmark$ & - & - & $\begin{array}{l}\text { * MEP improved in EMST group compared with control } \\
(p<0.05)\end{array}$ \\
\hline $\begin{array}{l}\text { Kulnik } \text { et al. } \\
(2015) \\
\text { UK [24] }\end{array}$ & $\mathrm{N}=42,64 \mathrm{y}, 65 \%$ male & Stroke & $\checkmark$ & - & PECF & $\begin{array}{l}\text { MEP and PEFR improved in treatment and sham } \\
\text { groups with no significant differences due to training. }\end{array}$ \\
\hline $\begin{array}{l}\text { Roth et al. } \\
(2010) \\
\text { USA [26] }\end{array}$ & $\mathrm{N}=29,30 y, 76 \%$ male & SCI & $\checkmark$ & FVC, FEV $_{1}$ & - & $\begin{array}{l}\text { MEP increased in training and sham groups but only } \\
\text { reached significance in training group }(p<0.05) \text { with } \\
\text { no significant changes in spirometry. }\end{array}$ \\
\hline
\end{tabular}

Abbreviations: N: number of subjects; y: years; MS: multiple sclerosis; COPD: chronic obstructive pulmonary disease; GOLD: Global initiative for Chronic Obstructive Lung Disease classification; SCI: spinal cord injury; MEP: maximum expiratory pressure; PFT: pulmonary function tests; FVC: forced vital capacity; $\mathrm{FEV}_{1}$ : forced expiratory volume in 1 second; PI: pulmonary index; PECF: peak expiratory cough flow; vs: versus; EMST: expiratory muscle strength training, * significant change $(p<0.05)$ in MEP vs control/sham. 
Table 2 Expiratory Muscle Strength Training - Intervention Parameters

\begin{tabular}{|c|c|c|c|c|c|c|c|}
\hline $\begin{array}{l}\text { Study } \\
\text { (year) }\end{array}$ & Subjects & $\begin{array}{l}\text { Threshold } \\
\text { Intensity }\end{array}$ & $\begin{array}{l}\text { Time/ } \\
\text { reps }\end{array}$ & $\begin{array}{l}\text { Frequency } \\
\text { (times per } \\
\text { week) }\end{array}$ & $\begin{array}{l}\text { Duration } \\
\text { (weeks) }\end{array}$ & Comparator & Device \\
\hline $\begin{array}{l}\text { Sasaki } \\
(2007) \text { [29] }\end{array}$ & Healthy & $30 \%$ & $\begin{array}{l}2 \times 15 \\
\min \end{array}$ & 7 & 4 & Control* & PEP \\
\hline $\begin{array}{l}\text { Suzuki et al. } \\
(1995)[17]\end{array}$ & Healthy & $30 \%$ & $\begin{array}{l}2 \times 15 \\
\min \end{array}$ & 7 & 4 & Control* & $\begin{array}{l}\text { Threshold } \\
\text { IMST }\end{array}$ \\
\hline $\begin{array}{l}\text { Mota et al. } \\
(2007)[25]\end{array}$ & COPD & $50 \%$ & $30 \mathrm{~min}$ & 3 & 5 & Sham* & $\begin{array}{l}\text { Threshold } \\
\text { IMST }\end{array}$ \\
\hline $\begin{array}{l}\text { Weiner et al. } \\
(2003) \text { [28] }\end{array}$ & COPD & $15-60 \%$ & $30 \mathrm{~min}$ & 6 & 12 & Control* & $\begin{array}{l}\text { Threshold } \\
\text { IMST }\end{array}$ \\
\hline $\begin{array}{l}\text { Gosselink et } \\
\text { al. }(2000)[18]\end{array}$ & MS & $60 \%$ & $\begin{array}{l}6 \times 15 \\
\text { reps }\end{array}$ & 7 & 12 & Control & $\begin{array}{l}\text { Threshold } \\
\text { IMST }\end{array}$ \\
\hline $\begin{array}{l}\text { Silverman et } \\
\text { al. } \quad(2017) \\
{[27]}\end{array}$ & MS & $75 \%$ & $\begin{array}{l}5 \times 5 \\
\text { reps }\end{array}$ & 5 & 5 & Sham** & PEP \\
\hline $\begin{array}{l}\text { Smeltzer et } \\
\text { al. (1996) [7] }\end{array}$ & MS & $\begin{array}{l}\text { Patient- } \\
\text { selected } \\
\text { maximum }\end{array}$ & $\begin{array}{l}6 \times 15 \\
\text { reps }\end{array}$ & 7 & 12 & Sham* & $\begin{array}{l}\text { Threshold } \\
\text { IMST }\end{array}$ \\
\hline $\begin{array}{l}\text { Kulnik et al. } \\
(2015) \text { [24] }\end{array}$ & Stroke & $50 \%$ & $\begin{array}{l}5 \times 10 \\
\text { reps }\end{array}$ & 7 & 4 & Sham** & PEP \\
\hline $\begin{array}{l}\text { Roth et al. } \\
(2010)[26]\end{array}$ & SCI & $\begin{array}{l}\text { Maximum } \\
\text { resistance }\end{array}$ & $\begin{array}{l}2 \times 10 \\
\text { reps }\end{array}$ & 5 & 6 & Sham* & $\begin{array}{l}\text { Closed end } \\
\text { pressure } \\
\text { meter }\end{array}$ \\
\hline
\end{tabular}

* Significant change $(p<0.05)$ in MEP vs control/sham; ** significant increase in MEP vs baseline but not vs sham.

Abbreviations: MS: multiple sclerosis; COPD: chronic obstructive pulmonary disease; SCI: spinal cord injury; PT: physiotherapy. *Significant $(p<0.05)$ increase in MEP following EMST vs control/sham.

Figure 2: Forrest plots illustrating change in maximum expiratory pressure (MEP) following expiratory muscle strength training (EMST) versus control: (A) all studies; (B) healthy subjects; (C) chronic obstructive pulmonary disease (COPD); (D) multiple sclerosis (MS).

A) All studies

\begin{tabular}{|c|c|c|c|c|c|c|c|c|c|c|}
\hline \multirow[b]{2}{*}{ Study or Subgroup } & \multicolumn{3}{|c|}{ EMST } & \multicolumn{3}{|c|}{ Control } & \multirow[b]{2}{*}{ Weight } & \multirow{2}{*}{$\begin{array}{l}\text { Mean Difference } \\
\text { IV, Random, } 95 \% \mathrm{CI}\end{array}$} & \multirow{2}{*}{\multicolumn{2}{|c|}{$\begin{array}{c}\text { Mean Difference } \\
\text { IV, Random, } 95 \% \mathrm{CI}\end{array}$}} \\
\hline & Mean & SD & Total & Mean & SD & Total & & & & \\
\hline GOSSELINK, R. et al., & 8 & 14 & 9 & -4 & 6.149 & 9 & $15.5 \%$ & $12.00[2.01,21.99]$ & & \\
\hline KULNIK, S.T. et al., & 12 & 15 & 21 & 12 & 18 & 21 & $15.5 \%$ & $0.00[-10.02,10.02]$ & & - \\
\hline MOTA, S., et al., 2007 & 24 & 37 & 10 & 1 & 1.26 & 6 & $7.8 \%$ & $23.00[0.05,45.95]$ & & \\
\hline ROTH, E.J., et al 2010 & 35 & 38.4 & 16 & 8 & 19.1 & 13 & $8.4 \%$ & $27.00[5.51,48.49]$ & & \\
\hline SASAKI, M., 2007. & 27.8 & 36.3 & 11 & -3.8 & 6.46 & 11 & $8.3 \%$ & $31.60[9.81,53.39]$ & & \\
\hline SILVERMAN E.P., et al., 2017 & 20.4 & 25.2 & 20 & 23.82 & 27.6 & 16 & $10.5 \%$ & $-3.42[-20.88,14.04]$ & & 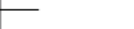 \\
\hline SMELTZER, S.C., LEVIETES, M.H. and COOK, S.D., & 19.4 & 9.9 & 10 & -1.2 & 11.1 & 5 & $14.4 \%$ & $20.60[9.10,32.10]$ & & $\longrightarrow$ \\
\hline SUZUKI, S., SATO, M. and OKUBO, T., & 37 & 35.2 & 6 & 0.01 & 0.01 & 6 & $5.9 \%$ & $36.99[8.82,65.16]$ & & \\
\hline WEINER, P. et al., 2003 & 18 & 22.2 & 12 & -1 & 1.7 & 11 & $13.6 \%$ & $19.00[6.40,31.60]$ & & $=$ \\
\hline Total $(95 \% \mathrm{Cl})$ & & & 115 & & & 98 & $100.0 \%$ & $15.95[7.77,24.12]$ & & \\
\hline $\begin{array}{l}\text { Heterogeneity: } \operatorname{Tau}^{2}=86.18 ; \mathrm{Ch}^{2}=20.36, \mathrm{df}= \\
\text { Test for overall effect: } Z=3.82(P=0.0001)\end{array}$ & $3(P=0$ & .009); & $I^{2}=61$ & & & & & & $\begin{array}{l}-50 \quad-25 \quad 0 \\
\text { Favours [Control] }\end{array}$ & $\begin{array}{cc}15 & 5 \\
\text { Favours [EMST] }\end{array}$ \\
\hline
\end{tabular}

B)

Healthy 


\begin{tabular}{|c|c|c|c|c|c|c|c|c|c|c|}
\hline \multirow[b]{2}{*}{ Study or Subgroup } & \multicolumn{3}{|c|}{ EMST } & \multicolumn{3}{|c|}{ Control } & \multicolumn{2}{|r|}{ Mean Difference } & \multirow{2}{*}{\multicolumn{2}{|c|}{$\begin{array}{l}\text { Mean Difference } \\
\text { IV, Fixed, } 95 \% \mathrm{CI}\end{array}$}} \\
\hline & Mean & SD & Total & Mean & SD & Total & Weight & IV, Fixed, $95 \% \mathrm{CI}$ & & \\
\hline SASAKI, M., 2007. & 27.8 & 36.3 & 11 & -3.8 & 6.46 & 11 & $62.6 \%$ & $31.60[9.81,53.39]$ & & \\
\hline SUZUKI, S., SATO, M. and OKUBO, T., & 37 & 35.2 & 6 & 0.01 & 0.01 & 6 & $37.4 \%$ & $36.99[8.82,65.16]$ & & \\
\hline Total $(95 \% \mathrm{Cl})$ & & & 17 & & & 17 & $100.0 \%$ & $33.62[16.38,50.85]$ & & \\
\hline $\begin{array}{l}\text { Heterogeneity: } \text { Chi }^{2}=0.09, \mathrm{df}=1(\mathrm{P} \\
\text { Test for overall effect: } \mathrm{Z}=3.82(\mathrm{P}=\end{array}$ & $\begin{array}{l}=0.77) ; \\
0001)\end{array}$ & $\mathrm{I}^{2}=0 \%$ & & & & & & & $\begin{array}{ll}-50 & -25 \\
\text { Favours [Control] }\end{array}$ & \begin{tabular}{|cc}
1 & 1 \\
& 50 \\
Favours [EMST]
\end{tabular} \\
\hline
\end{tabular}

C)

\begin{tabular}{|c|c|c|c|c|c|c|c|c|c|c|c|}
\hline \multirow[b]{2}{*}{ Study or Subgroup } & \multicolumn{3}{|c|}{ EMST } & \multicolumn{3}{|c|}{ Control } & \multicolumn{2}{|r|}{ Mean Difference } & \multirow{2}{*}{\multicolumn{3}{|c|}{$\begin{array}{l}\text { Mean Difference } \\
\text { IV, Fixed, } 95 \% \mathrm{CI}\end{array}$}} \\
\hline & Mean & SD & Total & Mean & SD & Total & Weight & IV, Fixed, 95\% CI & & & \\
\hline MOTA, S., et al., 2007 & 24 & 37 & 10 & 1 & 1.26 & 6 & $23.2 \%$ & $23.00[0.05,45.95]$ & & & \\
\hline WEINER, P. et al., 2003 & 18 & 22.2 & 12 & -1 & 1.7 & 11 & $76.8 \%$ & $19.00[6.40,31.60]$ & & & \\
\hline Total $(95 \% \mathrm{CI})$ & & & 22 & & & 17 & $100.0 \%$ & $19.93[8.88,30.97]$ & & & \\
\hline \multicolumn{9}{|c|}{$\begin{array}{l}\text { Heterogeneity: } \mathrm{Chi}^{2}=0.09, \mathrm{df}=1(P=0.76) ; I^{2}=0 \% \\
\text { Test for overall effect: } Z=3.54(P=0.0004)\end{array}$} & $\begin{array}{l}-50 \\
-50 \\
\text { Favou }\end{array}$ & $\begin{array}{ll}-25 & 0 \\
s \text { [Control] }\end{array}$ & Favours [EMST] \\
\hline
\end{tabular}

D) MS

\begin{tabular}{|c|c|c|c|c|c|c|c|c|c|c|}
\hline \multirow[b]{2}{*}{ Study or Subgroup } & \multicolumn{3}{|c|}{ EMST } & \multicolumn{3}{|c|}{ Control } & \multicolumn{2}{|r|}{ Mean Difference } & \multirow{2}{*}{\multicolumn{2}{|c|}{$\begin{array}{l}\text { Mean Difference } \\
\text { IV, Random, } 95 \% \mathrm{Cl}\end{array}$}} \\
\hline & Mean & SD & Total & Mean & SD & Total & Weight & IV, Random, $95 \% \mathrm{CI}$ & & \\
\hline GOSSELINK, R. et al., & 8 & 14 & 9 & -4 & 6.149 & 9 & $39.4 \%$ & $12.00[2.01,21.99]$ & & - - \\
\hline SILVERMAN E.P., et al., 2017 & 20.4 & 25.2 & 20 & 23.82 & 27.6 & 16 & $24.6 \%$ & $-3.42[-20.88,14.04]$ & & \\
\hline SMELTZER, S.C., LEVIETES, M.H. and COOK, S.D., & 19.4 & 9.9 & 10 & -1.2 & 11.1 & 5 & $36.0 \%$ & $20.60[9.10,32.10]$ & & - \\
\hline Total $(95 \% \mathrm{Cl})$ & & & 39 & & & 30 & $100.0 \%$ & $11.29[-0.32,22.91]$ & & \\
\hline $\begin{array}{l}\text { Heterogeneity: } \text { Tau }^{2}=63.20 ; \mathrm{Chi}^{2}=5.11, \mathrm{df}=2 \\
\text { Test for overall effect: } Z=1.91(\mathrm{P}=0.06)\end{array}$ & $=0.0$ & & $=61 \%$ & & & & & & 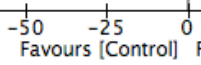 & ${ }^{25} 50$ \\
\hline
\end{tabular}

Figure 3: Forrest plot of change in peak expiratory cough flow (PECF) following expiratory muscle strength training (EMST) versus control

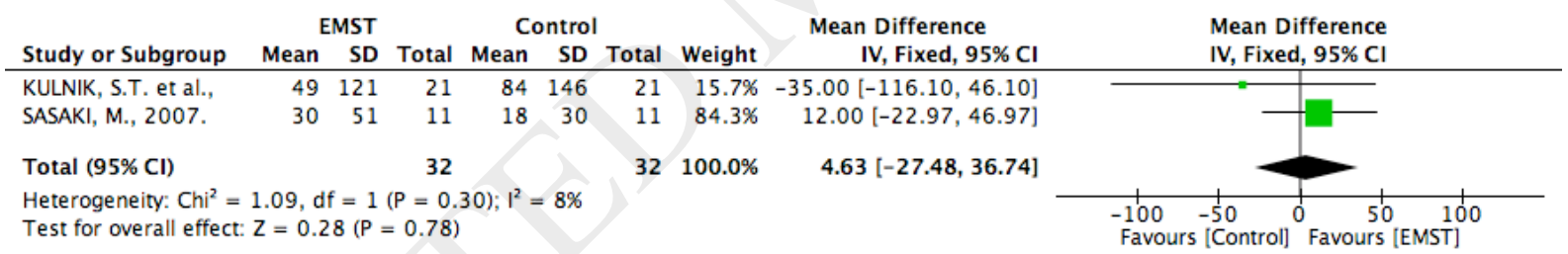

Figure 4: Forrest plot illustrating change in A) Forced vital capacity (FVC) or B) Forced expiratory volume in 1 second ( $\left.F E V_{1}\right)$ following expiratory muscle strength training (EMST) versus control.

A)

FVC

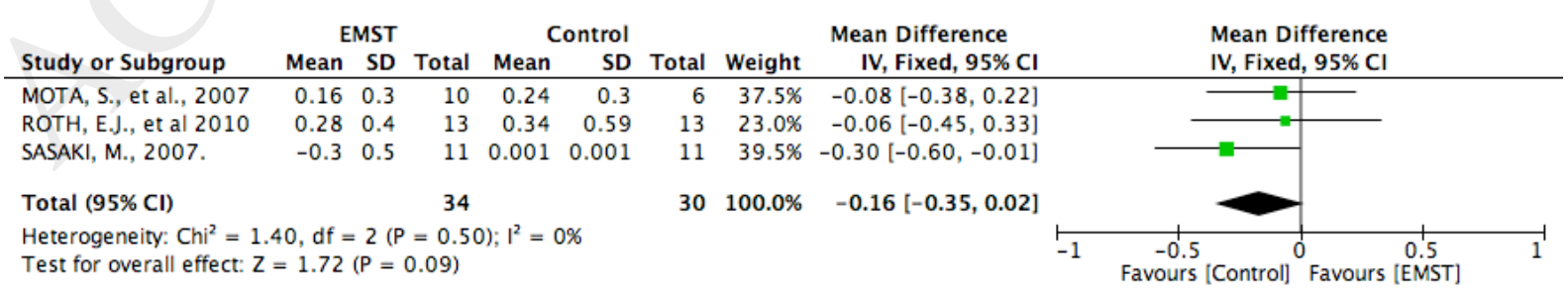

B)

$\mathrm{FEV}_{1}$ 


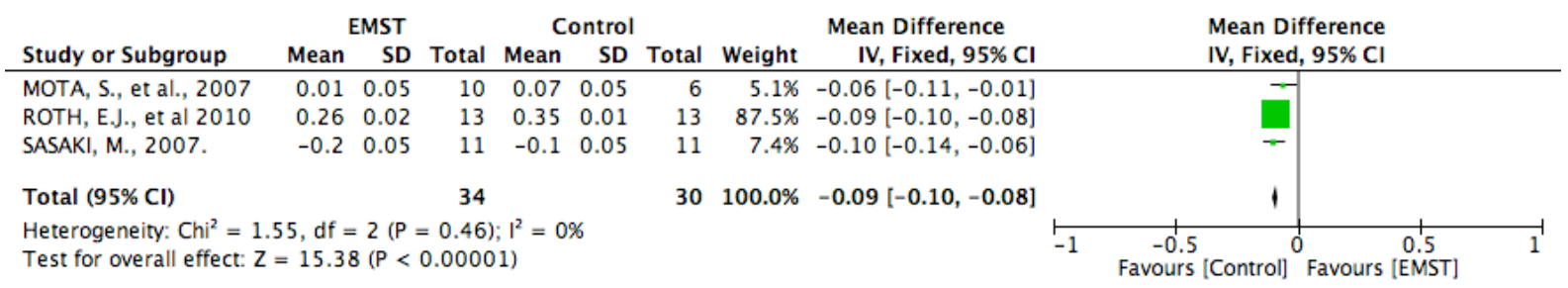

